\title{
Shift in feather mite distribution during the molt of passerines: the case of barn swallows (Hirundo rustica)
}

\author{
R. Jovani, D. Serrano, Ó. Frías, and G. Blanco
}

\begin{abstract}
Feather mites show a high diversity of distribution patterns on the wings of birds, but we are currently unable to make precise predictions about the distribution of mites on a given bird at a given time. This is especially intriguing because factors such as air turbulence, humidity, or temperature are already recognized as shaping feather mite distribution. We hypothesize that feather mites, rather than responding to single factors, respond at the same time to different constraints when deciding where to live. To test this hypothesis, we studied the distribution of mites along the wings of barn swallows (Hirundo rustica L., 1758) in Europe before molting and in Africa during and after molt. Feather mite preferences shifted according to the stage of molt of the bird, with a pattern suggesting a clear compromise between being as close as possible to the non-molting distribution while avoiding the molt of the occupied feather and the early stages of growth of new feathers. Thus, we suggest that interacting factors, rather than single variables, must be studied to further advance the understanding of the distribution of feather mites on the wings of birds.
\end{abstract}

Résumé : Les acariens des plumes présentent une grande diversité de patrons de répartition sur les ailes des oiseaux; il est, cependant, impossible à l’heure actuelle de faire des prédictions précises sur la répartition des acariens sur un oiseau particulier à un moment donné. Ce fait est assez intrigant puisqu'il est déjà reconnu que des facteurs tels que la turbulence de l'air, l’humidité et la température sont responsables de la répartition des acariens des plumes. Nous émettons l’hypothèse selon laquelle les acariens des plumes, plutôt que de réagir à des facteurs individuels, répondent simultanément à plusieurs contraintes différentes lorsqu’ils décident où se loger. Afin de tester cette hypothèse, nous avons étudié la répartition des acariens sur les ailes de l'hirondelle rustique (Hirundo rustica L., 1758) en Europe avant la mue et en Afrique pendant et après la mue. Les préférences des acariens des plumes changent en fonction du stade de la mue de l'oiseau selon un patron qui indique un net compromis entre la conformité la plus grande que possible avec la répartition hors de la période de mue, tout en évitant la mue de la plume habitée et les premiers stades de la croissance des nouvelles plumes. Ainsi, nous pensons qu'il faut étudier des facteurs en interaction plutôt que des variables isolées pour mieux comprendre la répartition des acariens des plumes sur les ailes des oiseaux.

[Traduit par la Rédaction]

\section{Introduction}

The wing feathers of live birds are the habitat of many feather mite species (Astigmata: vane mites; according to Dabert and Mironov 1999). Because of their ectothermic condition and fine cuticle, feather mites have highly specific humidity and temperature requirements, and are unable to survive for long off the bird (Dubinin 1951, pp. 188, 256). Therefore, from the point of view of feather mites, wing

Received 12 October 2005. Accepted 2 March 2006. Published on the NRC Research Press Web site at http://cjz.nrc.ca on 7 June 2006.

R. Jovani ${ }^{1}$ and D. Serrano. Departamento de Biología Aplicada, Estación Biológica de Doñana, Consejo Superior de Investigaciones Científicas (CSIC), Avenida $\mathrm{M}^{\mathrm{a}}$ Luisa s/n, E41013 Sevilla, Spain.

Ó. Frías. Oficina de Especies Migratorias, Dirección General para la Biodiversidad, Gran Vía de San Francisco 4, 28005 Madrid, Spain.

G. Blanco. Instituto de Investigación en Recursos Cinegéticos, CSIC - Universidad de Castilla - La Mancha, Ronda de Toledo s/n 13005 Ciudad Real, Spain.

${ }^{1}$ Corresponding author (e-mail: jovani@ebd.csic.es). feathers of birds are expected to be highly heterogeneous habitats, depending on wing morphology and bird behavior (flapping and fold-spread wing movements). In response to this environmental pressure, wing-dwelling feather mites often have the capacity to freely move among feathers, adopting different distributions along the wings of birds (e.g., Dubinin 1951, pp. 185, 278; Choe and Kim 1989; Wiles et al. 2000; Bridge 2003; Jovani and Serrano 2004), and even among individuals of the same bird species (Jovani and Serrano 2004). Although these movements may take only a few minutes, the location of mites is extremely similar between left and right wings of a given bird at a given time (Jovani and Serrano 2004). This suggests that the great diversity in distributions of feather mites among and within bird species is not the product of random movements of mites, but the outcome of their location decisions (i.e., habitat selection). Accordingly, habitat heterogeneity in terms of temperature, humidity, and aerodynamic challenges has been suggested as shaping the distribution of feather mites on different bird species and under different environmental circumstances (Dubinin 1951, pp. 257, 278; Choe and Kim 1989; McClure 1989; Wiles et al. 2000; Jovani and Serrano 2004).

However, these are not the only factors with a recognized potential for shaping the distribution of feather mites. Molt 
Table 1. Molt codes recorded from each primary feather.

\begin{aligned} & \hline Code Description \\ & \hline $1-3$ Old feather with three (1), two (2), or one (3) old feathers preceding its molt \\ & 4 Old feather next to be molted with the preceding feather in molt code 8 \\ & 5 Old feather next to be molted with the preceding feather in molt code 9 \\ & 6 Old feather next to be molted with the preceding feather in molt code 10 \\ & 7 Old feather next to be molted with the preceding feather in molt code 11 \\ & 8 Growing feather still on the feather follicle \\ & 9 Growing feather emerging from the feather follicle up to one-third grown \\ & 10 Growing feather between one and two-thirds grown \\ & 11 Growing feather more than two-thirds grown \\ & $12-19$ From the last (12) to the eighth (19) feather achieving its final length \\ & \hline\end{aligned}

(i.e., the regular replacement of old feathers by new ones) is a major threat for permanent ectosymbionts of bird feathers, so they act accordingly by avoiding those feathers that are going to be molted. In feather mites of passerine birds, Jovani and Serrano (2001) found that mites escaped from feathers close to be molted. This escape behavior could be an adaptive response to counteract a common environmental pressure that clearly is compromising their life expectancies (Jovani 2003). Moreover, this escape behavior has also been reported for other ectosymbionts living on the feathers of birds. For instance, Kethley (1971) wrote about quill mites (Acarina: Syringophilidae) that "Just before the old feathers are molted, the young females leave and disperse to newly developing quills.” Similarly, Moyer et al. (2002) found that feather lice congregate in the sheath of growing feathers, ensuring that they are on a feather which will not be molted soon. However, it could be hypothesized that this behavior has a cost in that ectosymbionts move to less suitable microhabitats in terms of aerodynamics, temperature, or humidity, perhaps reducing their normal performance and fitness during the bird's molting period.

Our aim here was to assess the behavioral response of feather mites to temporal changes in habitat characteristics by studying their distribution patterns along the wing feathers of molting and non-molting birds. We studied the distribution of feather mites on wild barn swallows (Hirundo rustica L., 1758) captured before molt (when in their European breeding areas), and during and just after molt (when in African wintering areas). In particular, we predicted that (i) mites should change their distribution along the wing of birds in relation to the stage of molt and (ii) mites should leave feathers that are close to being molted. Once these predictions were confirmed, we tested the two proposed mechanisms: (1) the "vibration hypothesis", which postulates that feather mites perceive the extra movement of a feather because it is starting to disengage from its sheath (Dubinin 1951, p. 235), and (2) the "window hypothesis", which states that mites note extra aeration because of the gap created by the previously molted feather (Jovani and Serrano 2001).

The barn swallow is a suitable study model for our purposes because it shows a well-defined pattern of feather mite distribution during the non-molting period (Dubinin 1951, p. 236; Blanco and Frías 2000). This is important because in other species such as the blackcaps (Sylvia atricapilla (L., 1758)) great intraspecific differences have been found in the distribution of mites along the wing of birds during the non-molting period (Jovani and Serrano 2004), which could make the comparison of the distribution of mites among birds at different stages of molt unreliable. Thus, we start with the assumption that the distribution pattern of feather mites along the wing of non-molting swallows reflects the environmental challenges imposed by temperature, humidity, and aerodynamics. Since the study of these factors on individual feathers of a flying bird is a very difficult task, we first used feather vane length, area, and feather position within the wing as three variables potentially related to habitat structure and suitability for the mites during the non-molting period. Moreover, barn swallows are slow-molting birds (see Methods), in contrast with the fast-molting species studied previously (Jovani and Serrano 2001). This means that the time elapsed between the loss of consecutive feathers in the molt sequence is much higher, and thus the gap and the vibration are nearly independent in time (see below) for a given feather position, allowing us to test the "vibration" and the "window".

\section{Methods}

\section{Study species}

Both adults and first-year barn swallows undergo a complete molt in their wintering areas in central Africa, and migrate northwards for breeding in spring (Jenni and Winkler 1994). The complete molt includes the sequential replacement of all the wing feathers of the bird. For primaries, feathers are replaced from the innermost (tenth primary) to the outermost (first primary) in consecutive order. Compared with other passerines of the same size, the duration of the molt is exceptionally long in barn swallows, extending up to 6 months (Ginn and Melville 1983; Turner and Rose 1989; Jenni and Winkler 1994). In the case of barn swallows, primaries are molted when the preceding feather in the molt sequence has grown to at least two thirds of its final length.

Most feather mites collected from primaries were identified as Pterodectes rutilus Mégnin in Robin and Mégnin, 1877 (Proctophyllodidae, Pterodictinae), although a small number of mites $(<1 \%)$ from two other species were also found.

\section{Field procedures}

During several ringing sessions, we captured non-molting barn swallows by attracting them to mist nets with taped songs at Laguna San Juan, Chinchón (40808’N, 03825’W; Ma- 
Fig. 1. Mean (+1 SE) proportion of feather mites on each primary feather of barn swallows (Hirundo rustica) at different stages of molt with respect to the total number of mites found in the primaries of each bird. Each panel summarizes the distribution of feather mites on a subset of birds $(N)$ at different stages of molt and in the different study countries, from pre-molting (A) up to post-molting birds (H). Barn swallows with active molt (from B to F) are grouped according to the feather next to be molted, i.e., "molt 5" refers to birds on which the following feather to be molted (i.e., to be lost) is the fifth primary. The location of the outermost (2) and the innermost (10) primaries is indicated. The molt stage of each primary is indicated in white (old), gray (growing), and black (new), both in the drawing and in the bars.
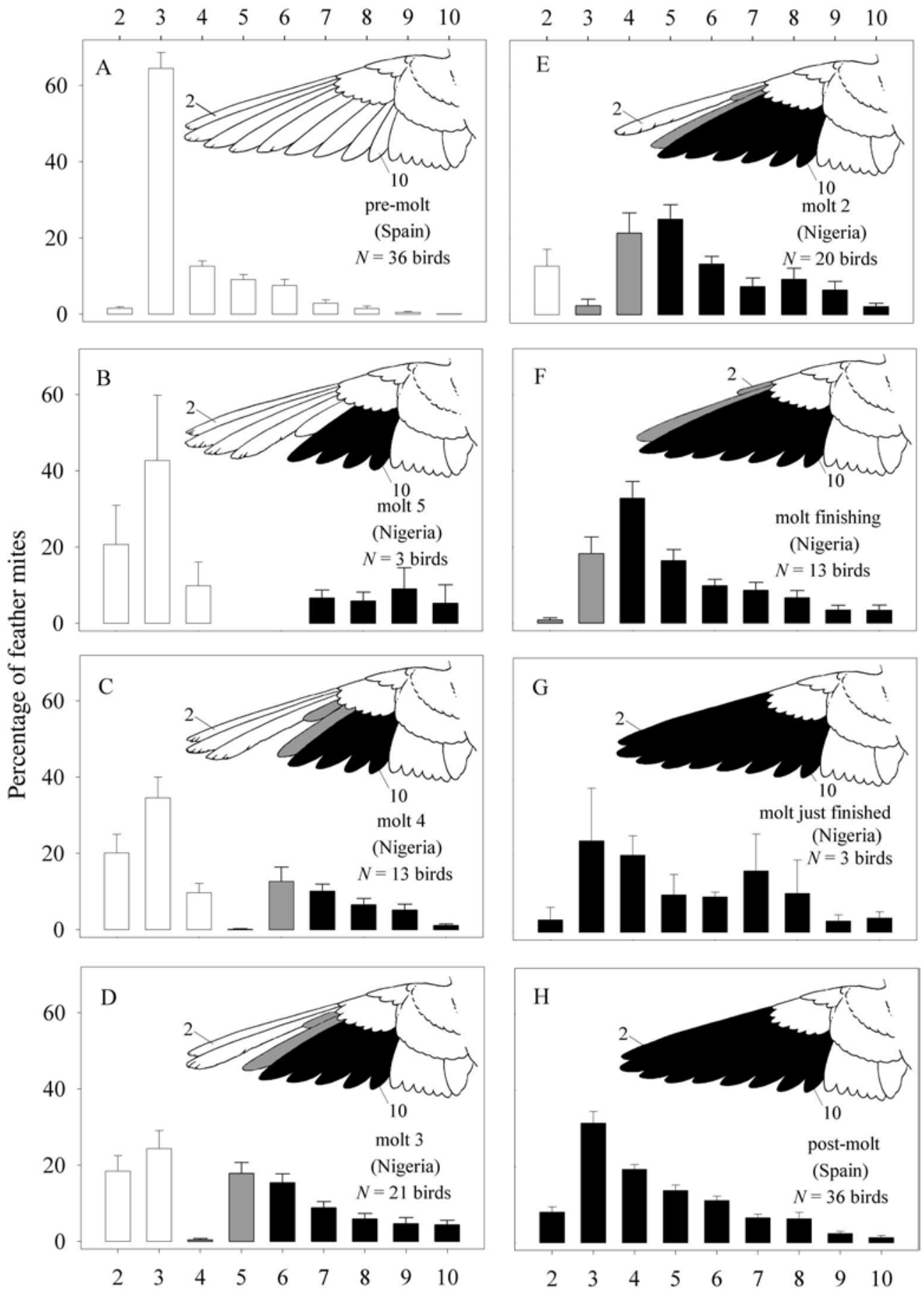

Primary feather

drid, Spain), before departure on (13 July - 4 August 1999) and shortly after arrival from (26 March - 9 April 2002) their trans-Saharan migration. We also captured barn swallows in active molt or recently finished molt in their winter areas at Ebaken Boje (06817'N, 08855'E; Cross
River State, Nigeria), from 16 January to 3 February 2001. Birds were kept individually in cloth bags, banded, examined for feather mites, and released. When we detected feather mites on a barn swallow, we counted them one by one on the flight feathers (i.e., primaries, secondaries, and 
tertials) of the right wing with the help of a $10 \times$ magnifying lens, exposing the wing to ambient light. The first (outermost) primary is very small in barn swallows, precluding the inspection of this feather for feather mites. We focused on the distribution of feather mites only on the primary feathers, since relatively few mites occurred on the secondaries $(3.5 \%)$ and tertials $(0.4 \%)$ in the sampled birds ( $N=145$ birds).

Benefiting from the high predictability of primary molt sequence, we recorded the stage of molt of each primary feather in a code from 1 to 19 (Table 1) that more clearly reflected the temporal proximity of molt for each feather, rather than the classic code of 6 categories (Ginn and Melville 1983), with the aim of studying in more detail the effect of the imminence of feather molt and the early stages of feather growth on the distribution of mites.

The feather mites under study are usually concentrated close to the feather rachis, but spread somewhat throughout the feather vane. Moreover, the primary feathers of barn swallows differ greatly in their morphology, some being long and stiff and others being short and weak. In this way, feather size could be indicative both of feather strength and habitat availability. Thus, we measured feather length and area from five barn swallows killed in collisions with cars as a measure of habitat characteristics. Vane length was measured with a ruler (nearest $0.5 \mathrm{~mm}$ ) and vane area using Adobe Photoshop ${ }^{1}$ version 5.0 .2 (nearest $0.1 \mathrm{~mm}^{2}$ ). For analyzing the relative importance of feather morphology and feather molt stage, we assumed that a feather in molt code 9 had reached one quarter, in code 10 had reached half, and in code 11 had reached three quarters of its full length.

\section{Statistical analyses}

The proportion of feather mites on a given feather is not expected to be normally distributed because of the aggregated distribution of mites among birds, and the same could apply to the number of feather mites per feather in a given bird. Therefore, we opted to use generalized lineal models (GLMs; see McCullagh and Nelder 1983) implemented in SAS $^{1}$ version 8.02 (SAS Institute Inc. 1997). In the way used here, GLMs are equivalent to conventional ANOVAs with the advantage that we can specify the distribution of the dependant variable and the way that the model relates the dependant variable with the independent variables (i.e., the so-called link function; for some examples see Herrera 2000).

Since maximum mite load on a given feather is heavily dependant on the total number of mites on the wing, and because of the high variability in the number of mites among barn swallows, we tried to use the proportion of mites on each primary as the response variable in the GLM, with the number of mites on each feather as the numerator and the total number of mites on all the primaries of each bird as the binomial denominator, following Crawley (1993). However, our data did not fit a binomial distribution of errors, showing overdispersion values above 20 on the GLM analyses (when it should have been around one; Crawley 1993). Thus, we searched for other distributions of errors that would better described the variance in our data. Gamma distribution of errors with a reciprocal link function imple-
Table 2. Wilcoxon's matched-pairs signed-rank tests for examining the difference in the number of feather mites occurring between the outermost primary feather (second primary) and its contiguous primary (third primary; for feather location see Fig. 1) on the 75 non-molting barn swallows studied.

\begin{tabular}{lc}
\hline Comparison & Number of birds \\
\hline 2nd primary $<$ 3rd primary & 71 \\
2nd primary $=$ 3rd primary & 2 \\
2nd primary $>$ 3rd primary & 2 \\
Wilcoxon's test & $Z=-7.296, P<0.0001$ \\
\hline
\end{tabular}

mented in the GENMOD procedure of SAS ${ }^{\mathbf{1}}$ correctly fitted the data, but since this distribution does not allow zero values, we overcame this problem by adding one mite to each of the nine primary feathers of each bird. Moreover, to avoid the error associated with proportions calculated from low sample sizes, we excluded from the analyses those individual barn swallows with fewer than 15 mites on their primaries (before adding the 9 mites stated above for statistical reasons; see Jovani and Tella 2006).

To test at the individual level the consistency of the apparent difference in mite load between the second and the third primary feathers found on non-molting birds (see Fig. 1), we carried out Wilcoxon's matched-pairs signedrank tests in SPSS ${ }^{\mathbf{1}}$ version 10.0 (SPSS Inc. 1999).

To examine how feather mite preferences changed during the annual cycle, we compared the position (from 2 to 10) of the feather with the most mites among birds at different stages of molt using a Kruskal-Wallis test in SPSS ${ }^{\mathbf{1}}$. In the few cases where a bird had equal numbers of mites on two contiguous feathers, we selected one at random, and when it occurred between non-adjacent feathers, we selected the midpoint between them. Tests are two-tailed throughout.

\section{Results}

We studied a total of 14414 feather mites from 145 barn swallows (for sample sizes in different molt stages see Fig. 1). Because of the late dates on which we sampled the barn swallows in the winter areas (January-February), we recorded birds at an advanced stage of molt, i.e., from individuals with the fifth primary about to be molted to birds with the molt recently finished.

\section{Wing morphology}

In non-molting barn swallows (i.e., birds with all the feathers fully grown), the second primary has the longest vane (mean $88.8 \mathrm{~mm}$, range 85-94 mm), gradually decreasing in length towards the innermost primary $(46.9 \mathrm{~mm}, 46-$ $48 \mathrm{~mm})$. Vane area increased from the second primary (mean $594.8 \mathrm{~mm}^{2}$, range $548.7-613.8 \mathrm{~mm}^{2}$ ) to the third primary $\left(623.2 \mathrm{~mm}^{2}\right.$, 586.9-682 $\left.\mathrm{mm}^{2}\right)$, then gradually decreased towards the innermost primary $\left(307.7 \mathrm{~mm}^{2}\right.$, 277.3$379 \mathrm{~mm}^{2}$ ).

\section{Non-molt distribution}

In $94.7 \%$ of non-molting barn swallows $(n=75)$, the outermost examinable primary (the second primary) had fewer mites than the third primary (Table 2), but on the whole, 
Fig. 2. Primary feathers preferred by mites in barn swallows along the annual cycle (for a picture of molt stages see Fig. 1). In each panel, the number of birds in which each feather was found to have the highest mite load in a bird is represented. For molting birds, an asterisk indicates the last molted primary (i.e., the front of molt).

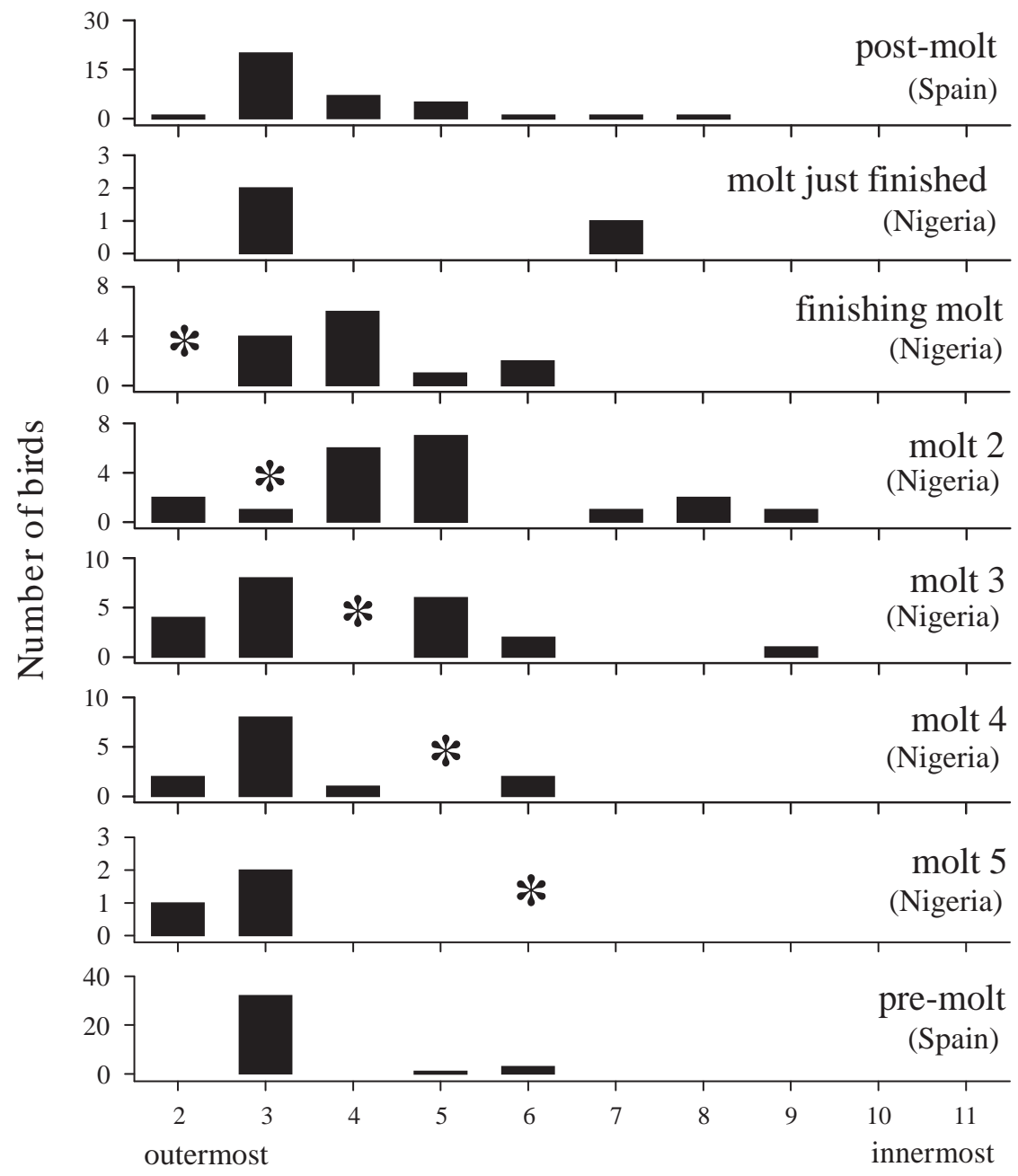

Primary feather

mite load increased from inner to outer primaries in all but one bird, this trend being significant in 57 birds with Spearman's $r$ value of $>0.67$ (all birds together: Spearman's $r$ mean (range) value of $0.78(-0.025,1)$; see also Fig. 1A). Accordingly, both vane length and area explained a considerable amount of variation of mite distribution when analyzed separately in non-molting birds (univariable GLM; vane length: $\boldsymbol{Z}_{\mathrm{H}_{11}}^{2}=262.89, P<0.0001$, explained deviance $=$ 28.7\%; vane area: $Z_{h 1]}^{2}=496.30, P<0.0001$, explained deviance $=47.7 \%)$.

\section{Molt distribution}

Feathers most used by mites changed during the annual cycle of barn swallows (Kruskal-Wallis; $z^{2}=26.81, P=$ 0.0003; Fig. 2). As soon as the molt front (i.e., location of the last molted primary) approached the third primary, mites changed their preference for this feather in non-molting birds to a preference for outer (second) or inner (fourth, up to ninth) primary feathers (Fig. 2). This implied that mites crossed the molt front to colonize those feathers that were finishing their growth (Figs. 1-3). Finally, in the last stages of the primary molt, and in birds with their molt just completed, mites returned to those feathers commonly preferred in non-molting birds in autumn or spring (Figs. 1, 2). Consistently, the code of molt of the feather explained $34.3 \%$ of the deviance for mite distribution in molting birds (univariable GLM; feather molt code: $Z_{\text {h18] }}^{2}=306.23, P<0.0001$; Fig. 3), and vane length and area explained $24.9 \%$ and $32.8 \%$, respectively (univariable GLM; vane length: $z_{\text {hi1 }}^{2}=$ 209.70, $P<0.0001$; vane area: $Z_{\sharp 1,1]}^{2}=289.55, P<0.0001$ ). In a multivariable GLM analysis, the code of molt and vane area were retained in the model (but not vane length; GLM, $\mathrm{Z}_{\sharp 1]}^{2}=1.81, P=0.178$ ), explaining a total of $39.1 \%$ of mite distribution (multivariable GLM; vane area: $Z_{\left.\eta_{1}\right]}^{2}=53.55$, $P<0.0001$; feather molt code: $z^{2}=70.22, P<0.0001$ ). Although both variables fitted jointly into the model, they contributed similar information, since vane area only explained $7.3 \%$ additional variance when feather molt code was fitted first into a type I model (i.e., in sequential order), and feather molt code explained an additional $9.4 \%$ of variance when the order of both effects was reversed, perhaps because mites prefer the outermost (biggest and 
Fig. 3. Effect of the molt stage of a feather on its mite load (for definitions of molt codes see Table 1) in the 70 molting barn swallows studied. Bars indicate the mean $+1 \mathrm{SE}$ of the percentage of mites on each feather with respect to the rest of the primaries of each bird. The number below each bar indicates the number of feathers studied at each molt code.

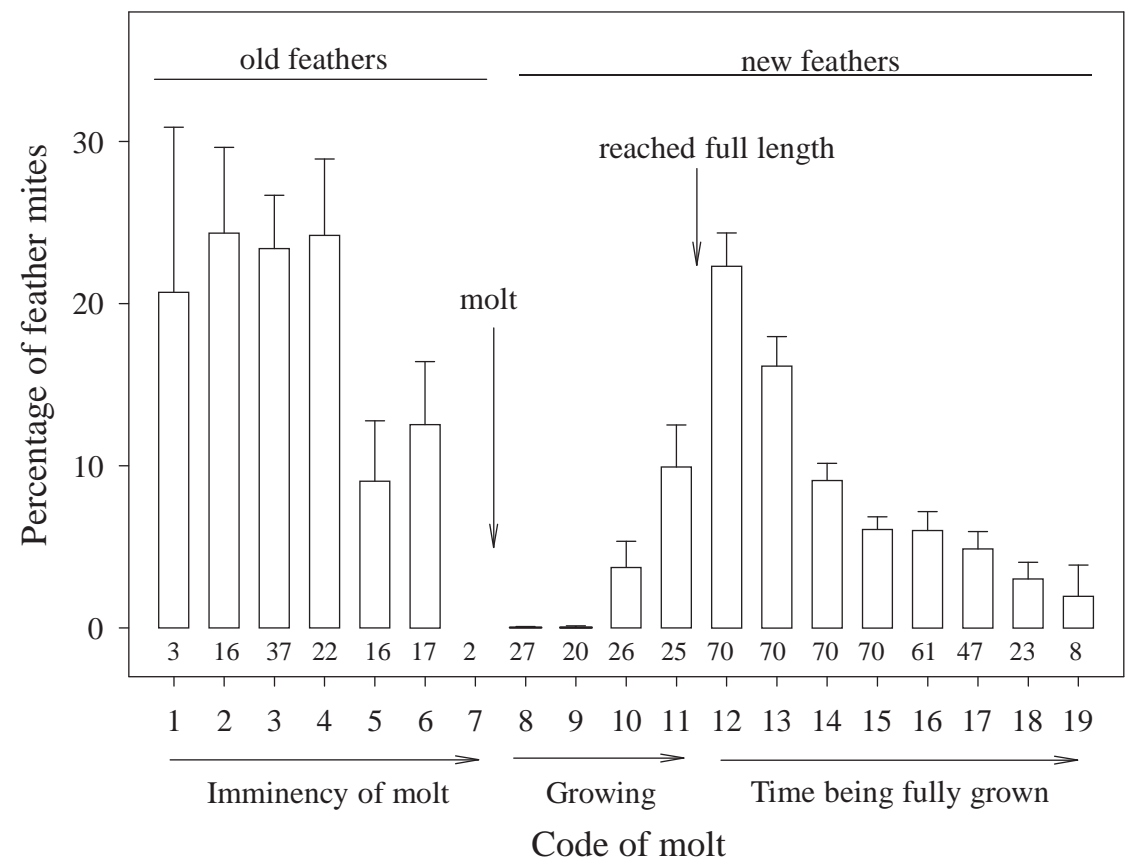

stiffest) feathers, and they exhibit slow colonization of growing, and thus smaller, feathers.

\section{Discussion}

In non-molting barn swallows, mites showed a preference for outer (and longer) primary feathers. However, this trend disappeared on the second primary (i.e., the outermost primary, in fact, since the first primary is almost nonexistent), which had fewer mites than the third primary in almost all non-molting birds studied. Since the second and third primaries were similar in size, this result supports the earlier observation by Jovani and Serrano (2004) that feather mites select where to live at the feather level, showing clear preferences even among contiguous feathers with similar morphology. The second primary is the feather that "cuts the wind" during the prolonged flights of barn swallows, and covers the ventral surface (i.e., where mites live) of the third primary. Therefore, we believe that the most plausible explanation is that mites avoid the outermost primary of barn swallows because of particular aerodynamic challenges, rather than morphological or structural constraints.

During molt, mites were distributed more evenly on the primaries of birds, with the distribution depending on the stage of molt. During the first stages of molt, mites showed distributions similar to that on non-molting barn swallows. However, when molt advanced and its front reached the third primary (the preferred feather in non-molting birds), mites shifted to a bimodal distribution with the "valley" placed where the molt was active. As molt advanced (see complementary views on Figs. 1-3), mites returned to their non-molting distribution. This finding is in agreement with our predictions, since mites shifted their preferences according to the stage of molt of the bird, with a pattern suggesting a compromise between being as close as possible to the nonmolting distribution while avoiding the molt and the early stages of growth of the feathers.

At first glance, our results could give the impression that the escape behavior of mites from barn swallow feathers about to be molted is not as efficient as that reported by Jovani and Serrano (2001) in other passerine species. This is because many feathers in the next position to be molted had considerable mite loads (see Figs. 1, 3). However, no mite was found on the two birds with a feather very close to be molted (in molt code 7), which is in contrast with the rest of the primaries of these two birds that harbored 42 and 140 mites, respectively (Fig. 3). We therefore believe that our results do not suggest that mites inhabiting barn swallows are poorly adapted to habitat disruptions imposed by the molt. Rather, we believe that the results are obscured by the slow molt of barn swallows. Thus, the same mite behavior (escaping from feathers soon to be molted) presumably resulted in very low mite loads in any feather in the next position of molt in fast-molting passerines (such as described in Jovani and Serrano 2001), but only on those feathers actually about to be molted in slow-molting birds (this study).

The very similar mite load in feathers in molt code 4 compared with those in molt codes 1-3 (Fig. 3) contradicts the "window" hypothesis suggested by Jovani and Serrano (2001), whereas the decline from molt codes 4 to 5 and 6, and the absence of mites in molt code 7 (just prior to loss, Fig. 3), seem to give more support to the "vibration" hypothesis proposed by Dubinin (1951, p. 235). This is because in molt code 4 the "window" has already been created, but mites did not leave the next feather to be molted until it had reached molt code 7 , when it was presumed that mites could detect abnormal vibration of the feather and when the "window" had almost disappeared because of the 
advanced stage of growth of the preceding feather in the molt sequence. Moreover, the "window" hypothesis was not able to explain easily why recently fully grown feathers (code 12) had a great number of mites (Fig. 3), since these mites were also close to the gap created by feathers that were still growing (see diagrams in Fig. 1).

The results reported here clearly show that the molt of birds greatly affects feather mite distribution on the wing of birds. Thus, failing to consider bird molt could lead to the misinterpretation of factors that shape the distribution of feather mites on the wings of birds. For instance, Wiles et al. (2000) found that feather mites from blue tits (Parus caeruleus L., 1758) shifted from being concentrated on the inner wing feathers (mainly tertials) during winter months to being more evenly distributed during late spring, summer, and autumn. They concluded from these observations that mite distribution was affected by ambient temperature rather than by season per se. The authors did not specify whether they included molting birds in the analyses. However, blue tits molt once a year, adult blue tits performing their complete molt from early May to late September, and first-year birds undergo a partial molt from mid-July to early October, when they replace body feathers and a variable number of wing coverts, tertials, and tail feathers (Ginn and Melville 1983; Jenni and Winkler 1994). Therefore, many birds captured by Wiles et al. (2000) were probably molting. We do not question the importance of ambient temperature as an important factor in shaping feather mite distribution within the wings of birds (also discussed in both Dubinin 1951, p. 167, and McClure 1989). However, we suggest that the seasonal changes in mite distribution could at least in part be due to covariation between warm seasons and molting timing in the blue tit.

In conclusion, we have found that feather mites on barn swallows (i) undertake precise location decisions at the feather level, discriminating among contiguous feathers with similar morphology; (ii) escape from feathers actually close to being molted; (iii) may detect that a feather is about to be molted by feather vibration (the "vibration" hypothesis; Dubinin 1951, p. 235), although a more direct test of this hypothesis is needed; and (iv) distribute themselves in a way that seems to be dictated by a compromise between being as close as possible to the large outer primaries (but not the outermost one) and avoiding those feathers about to be molted and in the early stages of growth.

\section{Acknowledgements}

We thank Pierfrancesco Micheloni (EURING Swallow project coordinator in Nigeria) for giving Ó.F. the opportunity to take part in that project and in helping with data collection. We thank the many individuals at little Ebaken Boje who provided great hospitality. We also thank Warren T. Atyeo for identifying the feather mites, Francisco José Hernández for making the figures, and Robert Sutcliffe for helping with the English. Instituto Nacional Para la Conservación de la Naturaleza (Madrid) Ringing Scheme and Comunidad de Madrid supplied the licenses to conduct this study.

\section{References}

Blanco, G., and Frías, Ó. 2000. Symbiotic feather mites synchronize dispersal and population growth with host sociality and migratory disposition. Ecography, 24: 113-120.

Bridge, E.S. 2003. Densities and distribution of commensal feather mites (Zachvatkinia caspica) among the primaries of caspian terns. Int. J. Acarol. 29: 389-398.

Choe, J.C., and Kim, K.C. 1989. Microhabitat selection and coexistence in feather mites (Acari: Analgoidea) on Alaskan seabirds. Oecologia (Berl.), 79: 10-14. doi:10.1007/BF00378233.

Crawley, M.J. 1993. GLIM for Ecologists. Blackwell Scientific Publications, Oxford.

Dabert, J., and Mironov, S.V. 1999. Origin and evolution of feather mites (Astigmata). Exp. Appl. Acarol. 23: 437-454. doi:10. 1023/A:1006180705101.

Dubinin, V.B. 1951. Feather mites (Analgesoidea). Part I. Introduction to their study. Fauna SSSR Paukoobraznye, 6: 1-363.

Ginn, H.B., and Melville, D.S. 1983. Molt in birds. BTO guide 19. British Trust for Ornithology, Hertfordshire, UK.

Herrera, C.M. 2000. Flower-to-seedling consequences of different pollination regimes in an insect-pollinated shrub. Ecology, 81: 15-29.

Jenni, L., and Winkler, R. 1994. Molt and ageing of European passerines. Academic Press, London.

Jovani, R. 2003. Understanding parasite strategies. Trends Parasitol. 19: 15-16. doi:10.1016/S1471-4922(02)00007-7. PMID: 12488217.

Jovani, R., and Serrano, D. 2001. Feather mites (Astigmata) avoid molting wing feathers of passerine birds. Anim. Behav. 62: 723727. doi:10.1006/anbe.2001.1814.

Jovani, R., and Serrano, D. 2004. Fine-tuned distribution of feather mites (Astigmata) on the wing of birds: the case of blackcaps Sylvia atricapilla. J. Avian Biol. 35: 16-20. doi:10.1111/j.09088857.2004.03213.x.

Jovani, R., and Tella, J.L. 2006. Parasite prevalence and sample size: misconceptions and solutions. Trends Parasitol. 22: 214218. doi:10.1016/j.pt.2006.02.011.

Kethley, J. 1971. Population regulation in quill mites (Acarina: Syringophilidae). Ecology, 52: 1113-1118.

McCullagh, P., and Nelder, J.A. 1983. Generalized linear modelling. Chapman \& Hall, London.

McClure, H.E. 1989. Occurrence of feather mites (Proctophyllodidae) among birds of Ventura County Lowlands, California. J. Field Ornithol. 60: 431-450.

Moyer, B.R., Gardiner, D.W., and Clayton, D.H. 2002. Impact of feather molt on ectoparasites: looks can be deceiving. Oecologia (Berl.) , 131: 203-210.

SAS Institute Inc. 1997. SAS/STAT ${ }^{\mathbf{1}}$ software: changes and enhancements through release 6.12. SAS Institute Inc., Cary, N.C.

SPSS Inc. 1999. SPSS ${ }^{\mathbb{1}}$. Version 10.0 [computer program]. SPSS Inc., Chicago.

Turner, A., and Rose, C. 1989. A Handbook to the Swallows and Martins of the World. Cristopher Helm, Oxford.

Wiles, P.R., Cameron, J., Behnke, J.M., Hartley, I.R., Gilbert, F.S., and McGregor, P.K. 2000. Season and ambient air temperature influence the distribution of mites (Proctophyllodes stylifer) across the wings of blue tits (Parus caeruleus). Can. J. Zool. 78: 1397-1407. doi:10.1139/cjz-78-8-1397. 